Report:

\title{
Cancer incidence and mortality in the United Kingdom and constituent countries, 2004-06
}

\section{Susan Westlake Office for National Statistics}

\section{Introduction}

This report presents the numbers of newly diagnosed cases of cancer (incidence) and deaths from cancer (mortality) in the UK during 2004-06, together with the age-standardised incidence and mortality rates. The report covers all cancers combined (excluding the incidence of non-melanoma skin cancer), and 21 common cancers. Results are given for the UK as a whole and for its four constituent countries. Numbers and age-standardised rates have been calculated as averages over the three-year period 2004-06 (See Background notes).

\section{Key findings}

- Around 147,000 males and 146,000 females on average were newly diagnosed with cancer each year in the UK during 2004-06, corresponding to an incidence rate of 414 and 356 per 100,000 respectively

- Around 80,000 males and 74,000 females on average died from cancer each year in the UK, corresponding to a mortality rate of 218 and 155 per 100,000 respectively

- In females, breast cancer had the highest incidence rate in the UK (122 per 100,000), 24 per cent higher than the cancer with the highest incidence in males - prostate cancer ( 98 per 100,000)

- Wales had the highest overall cancer incidence rate for males, which was 11 per cent higher than the UK average, while Scotland had the highest incident rate for females (8 per cent higher than the UK average)

- Scotland had the highest overall mortality rates for both males and females, at 17 per cent and 16 per cent higher than the UK average, respectively
The major cancers included in the tables and figures presented here accounted for almost 90 per cent of all cases of cancer, and just over 80 per cent of all deaths from cancer, in the UK in 2004-06. The three most common cancers accounted for around 50 per cent of both cases and deaths from cancer.

\section{Incidence}

There were on average around 293,000 newly diagnosed cases of cancer each year in the UK in 2004-06, with around 147,000 cases among males and 146,000 among females. Although there were almost identical numbers of cases among males and females, the overall age-standardised incidence rate was higher among males -414 per 100,000 compared with 356 per 100,000 for females (Table 1 ).

The three most common cancers were prostate, lung and colorectal for males, and breast, lung and colorectal for females (Figure 1). The incidence of lung cancer was 68 per cent higher in males than in females (62 and 37 per 100,000 respectively), and the incidence of colorectal cancer was 58 per cent higher in males ( 55 and 35 per 100,000 for males and females, respectively). Overall, breast cancer in females had the highest incidence rate (122 per 100,000), 24 per cent higher than the cancer with the highest incidence in males - prostate cancer $(98$ per 100,000).

\section{Mortality}

There were on average 154,000 deaths from cancer each year in the UK in 2004-06, with around 80,000 deaths among males and 74,000 among females. The equivalent age-standardised mortality rates were 218 and 155 per 100,000 among males and females, respectively (Table 2).

The three most common cancers for both sexes were also the most common causes of death from cancer (Figure 2). However, for females the mortality rate was slightly lower for breast than for lung cancer (28 and 31 per 100,000 respectively). For males, the mortality rate for lung cancer $(53$ per 100,000$)$ was twice as high as that for prostate cancer ( 26 per 100,000). Overall, the highest mortality rate was for lung cancer in males. The mortality rate for lung cancer was 75 per cent higher in males than in females. The mortality rate for colorectal cancer was 59 per 


\begin{tabular}{|c|c|c|c|c|c|c|c|c|c|c|c|c|}
\hline Table 1 & \multicolumn{12}{|c|}{$\begin{array}{l}\text { Registrations of newly diagnosed cases of cancer and directly age-standardised }{ }^{1} \text { incidence rates per } 100,000 \text { population: } \\
\text { selected sites by sex and country, 2004-06 }\end{array}$} \\
\hline \multirow[t]{2}{*}{ ICD-10 } & \multirow[t]{2}{*}{ Site description } & \multirow[t]{2}{*}{ Sex } & \multicolumn{2}{|c|}{ United Kingdom } & \multicolumn{2}{|c|}{ England } & \multicolumn{2}{|c|}{ Wales } & \multicolumn{2}{|c|}{ Scotland } & \multicolumn{2}{|c|}{$\mathrm{N}$ Ireland } \\
\hline & & & Number & Rate & Number & Rate & Number & Rate & Number & Rate & Number & Rate \\
\hline \multirow[t]{2}{*}{$\mathrm{C} 00-\mathrm{C} 97$} & All malignancies ${ }^{3}$ & M & 146,790 & 414.0 & 121,241 & 407.8 & 8,737 & 459.8 & 13,224 & 446.1 & 3,588 & 411.6 \\
\hline & & $F$ & 145,731 & 355.6 & 119,903 & 351.2 & 8,175 & 377.7 & 14,017 & 385.7 & 3,636 & 347.1 \\
\hline \multirow[t]{2}{*}{$\mathrm{C} 00-\mathrm{C} 14$} & Lip, mouth and pharynx & M & 3,821 & 11.7 & 3,011 & 11.1 & 228 & 13.5 & 476 & 16.9 & 107 & 12.7 \\
\hline & & $\mathrm{F}$ & 2,031 & 5.2 & 1,642 & 5.0 & 110 & 5.5 & 222 & 6.5 & 57 & 5.5 \\
\hline \multirow[t]{2}{*}{ C15 } & Oesophagus & M & 5,005 & 14.2 & 4,095 & 13.8 & 273 & 14.3 & 525 & 17.8 & 112 & 13.1 \\
\hline & & $\mathrm{F}$ & 2,779 & 5.6 & 2,251 & 5.5 & 157 & 6.1 & 318 & 7.4 & 53 & 4.4 \\
\hline \multirow[t]{2}{*}{ C16 } & Stomach & M & 5,133 & 14.0 & 4,201 & 13.6 & 313 & 16.2 & 492 & 16.1 & 127 & 14.3 \\
\hline & & $\mathrm{F}$ & 2,886 & 5.7 & 2,291 & 5.4 & 190 & 6.8 & 317 & 7.3 & 88 & 7.0 \\
\hline \multirow[t]{2}{*}{ C18-C20 } & Colorectal & M & 19,935 & 55.4 & 16,355 & 54.2 & 1,146 & 59.0 & 1,880 & 62.4 & 554 & 63.2 \\
\hline & & $\mathrm{F}$ & 16,398 & 35.0 & 13,452 & 34.3 & 888 & 36.0 & 1,602 & 39.1 & 456 & 39.9 \\
\hline \multirow[t]{2}{*}{$\mathrm{C} 25$} & Pancreas & M & 3,728 & 10.4 & 3,136 & 10.5 & 211 & 11.0 & 290 & 9.7 & 91 & 10.6 \\
\hline & & $\mathrm{F}$ & 3,945 & 8.2 & 3,312 & 8.2 & 226 & 8.6 & 321 & 7.9 & 87 & 7.1 \\
\hline \multirow[t]{2}{*}{ C32 } & Larynx & M & 1,809 & 5.3 & 1,429 & 5.0 & 91 & 5.0 & 232 & 8.1 & 58 & 6.8 \\
\hline & & $\mathrm{F}$ & 394 & 1.0 & 289 & 0.9 & 22 & 1.0 & 68 & 2.0 & 14 & 1.4 \\
\hline \multirow[t]{2}{*}{ C34 } & Lung & M & 22,637 & 62.3 & 18,254 & 59.9 & 1,280 & 65.6 & 2,537 & 83.7 & 566 & 64.1 \\
\hline & & $F$ & 16,487 & 37.0 & 12,996 & 35.0 & 950 & 40.4 & 2,170 & 55.2 & 370 & 33.7 \\
\hline \multirow[t]{2}{*}{ C43 } & Melanoma of skin & M & 4,458 & 13.4 & 3,716 & 13.4 & 223 & 13.0 & 415 & 14.8 & 105 & 12.3 \\
\hline & & $\mathrm{F}$ & 5,298 & 14.7 & 4,403 & 14.6 & 259 & 13.8 & 496 & 15.7 & 140 & 14.4 \\
\hline C50 & Breast & $\mathrm{F}$ & 45,524 & 122.3 & 38,046 & 122.8 & 2,398 & 122.7 & 4,012 & 120.8 & 1,068 & 109.7 \\
\hline C53 & Cervix & $\mathrm{F}$ & 2,824 & 8.3 & 2,280 & 8.0 & 164 & 10.0 & 290 & 9.9 & 89 & 9.8 \\
\hline C54 & Uterus & $\mathrm{F}$ & 6,510 & 16.9 & 5,424 & 16.9 & 394 & 19.5 & 520 & 15.3 & 172 & 17.7 \\
\hline C56 & Ovary & $\mathrm{F}$ & 6,627 & 17.1 & 5,467 & 16.9 & 382 & 18.7 & 590 & 17.1 & 188 & 19.0 \\
\hline C61 & Prostate & M & 35,552 & 98.3 & 29,953 & 98.9 & 2,228 & 112.6 & 2,571 & 85.0 & 800 & 91.5 \\
\hline C62 & Testis & M & 2,070 & 6.9 & 1,697 & 6.8 & 104 & 7.6 & 206 & 8.3 & 62 & 7.4 \\
\hline \multirow[t]{2}{*}{ C64 } & Kidney & M & 4,041 & 11.8 & 3,303 & 11.5 & 256 & 14.0 & 385 & 13.3 & 97 & 11.4 \\
\hline & & $\mathrm{F}$ & 2,462 & 6.0 & 1,998 & 5.8 & 154 & 7.0 & 242 & 6.5 & 68 & 6.6 \\
\hline C67 & Bladder & M & 7,318 & 19.7 & 6,005 & 19.2 & 663 & 33.9 & 502 & 16.4 & 148 & 16.6 \\
\hline & & $\mathrm{F}$ & 2,965 & 5.9 & 2,395 & 5.6 & 256 & 10.1 & 252 & 5.8 & 62 & 5.2 \\
\hline $\mathrm{C} 71$ & Brain & M & 2,554 & 7.9 & 2,144 & 7.9 & 134 & 8.0 & 213 & 7.7 & 63 & 7.4 \\
\hline & & $\mathrm{F}$ & 1,805 & 4.9 & 1,495 & 4.9 & 108 & 5.9 & 154 & 4.9 & 47 & 5.0 \\
\hline C81-C96 & Lymphomas and leukaemias & M & 13,062 & 38.2 & 10,851 & 37.8 & 765 & 42.2 & 1,114 & 39.1 & 331 & 38.2 \\
\hline & & $\mathrm{F}$ & 10,624 & 25.5 & 8,751 & 25.2 & 629 & 28.2 & 957 & 26.2 & 287 & 26.8 \\
\hline C81-C85 & Lymphomas & M & 6,428 & 19.1 & 5,387 & 19.1 & 339 & 19.3 & 542 & 19.2 & 160 & 18.5 \\
\hline & & $\mathrm{F}$ & 5,550 & 13.8 & 4,583 & 13.7 & 297 & 14.0 & 516 & 14.6 & 154 & 14.6 \\
\hline C81 & Hodgkin's disease & M & 886 & 2.9 & 740 & 2.9 & 40 & 2.6 & 81 & 3.2 & 26 & 3.0 \\
\hline & & $\mathrm{F}$ & 696 & 2.2 & 582 & 2.2 & 31 & 2.0 & 64 & 2.3 & 19 & 2.1 \\
\hline $\mathrm{C} 82-\mathrm{C} 85$ & Non-Hodgkin's lymphoma & M & 5,542 & 16.2 & 4,647 & 16.2 & 299 & 16.7 & 461 & 16.1 & 134 & 15.5 \\
\hline & & $\mathrm{F}$ & 4,855 & 11.7 & 4,001 & 11.6 & 266 & 12.0 & 452 & 12.2 & 135 & 12.5 \\
\hline $\mathrm{C} 90$ & Multiple myeloma & M & 2,184 & 6.1 & 1,789 & 6.0 & 130 & 6.8 & 188 & 6.3 & 77 & 8.8 \\
\hline & & $\mathrm{F}$ & 1,842 & 4.0 & 1,499 & 3.9 & 122 & 4.9 & 165 & 3.9 & 56 & 5.0 \\
\hline C91-C95 & Leukaemia & M & 4,275 & 12.5 & 3,536 & 12.3 & 283 & 15.4 & 364 & 12.9 & 91 & 10.6 \\
\hline & & $\mathrm{F}$ & 3,125 & 7.4 & 2,585 & 7.3 & 201 & 8.8 & 264 & 7.5 & 75 & 7.1 \\
\hline
\end{tabular}

1 Using the European standard population.

2 All numbers and rates in this table are calculated as three-year averages.

3 Figures exclude non-melanoma skin cancer (ICD-10 C44). 

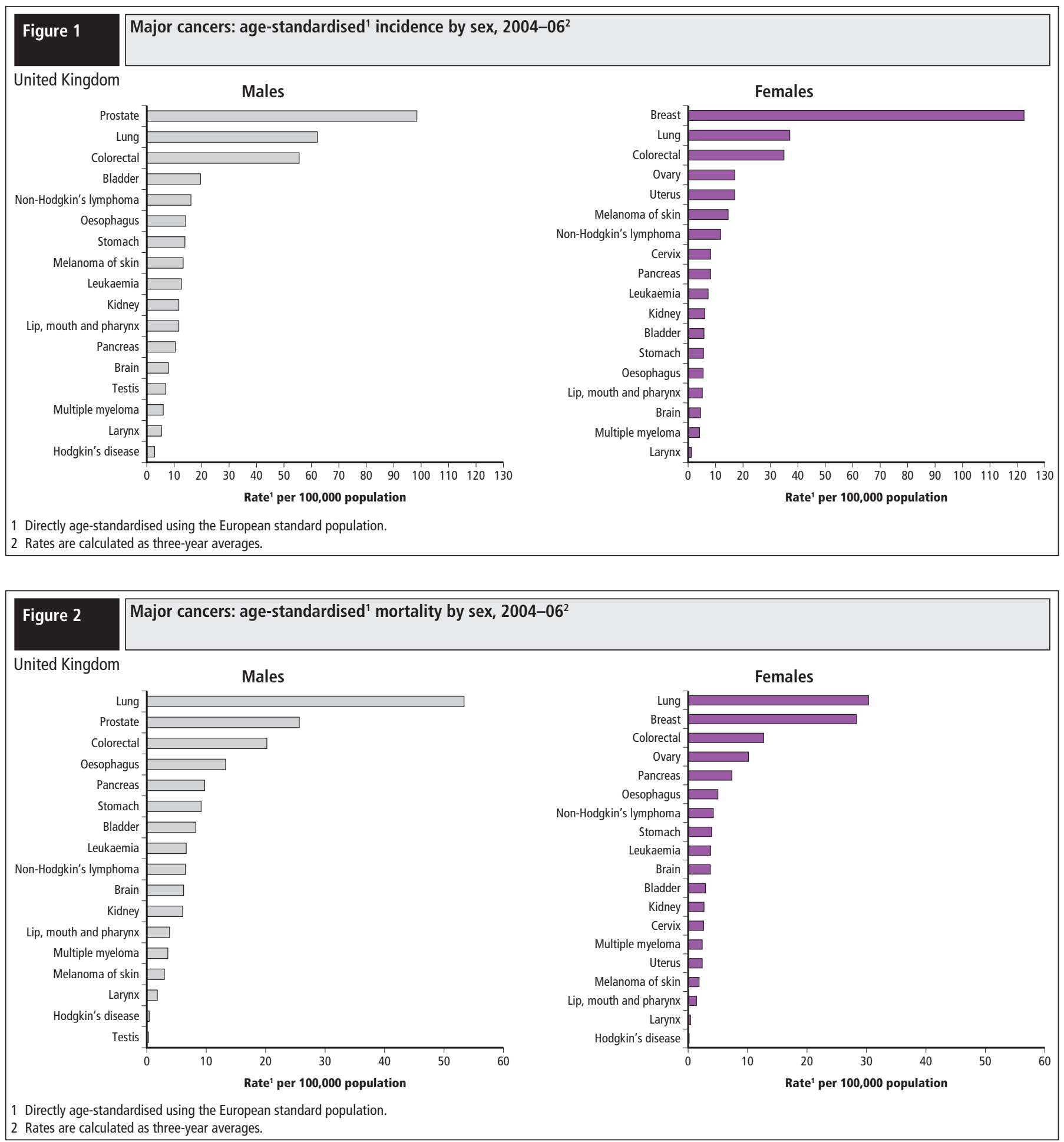

cent higher in males than females ( 20 and 13 per 100,000 for males and females respectively).

\section{Variations between countries}

Lung cancer incidence and mortality rates for both sexes were much higher in Scotland than in the rest of the UK (Figure 3). Rates in Wales, Northern Ireland and England were fairly similar.

For colorectal cancer, the incidence rates were similar in each country but highest in Northern Ireland. However, Scotland and Northern Ireland had much higher mortality rates than England and Wales (Figure 4).
Breast cancer incidence and mortality rates were similar in England, Wales and Scotland, but incidence was lower in Northern Ireland.

Incidence rates for prostate cancer varied, with Wales having the highest and Scotland the lowest, while mortality rates were very similar in each country (Tables 1 and 2).

Scotland had the highest incidence and mortality rates for oesophageal cancer, while Northern Ireland had the lowest (Figure 5).

For stomach cancer, Wales had the highest male incidence rate and England the lowest (Figure 6). For females, incidence was similar in Scotland, Wales and Northern Ireland but lower in England. Stomach 


\begin{tabular}{|c|c|c|c|c|c|c|c|c|c|c|c|c|}
\hline Table 2 & \multicolumn{12}{|c|}{$\begin{array}{l}\text { Table } 2 \text { Deaths from cancer and directly age-standardised' mortality rates per 100,000 population: selected sites by sex and } \\
\text { country, 2004-06² }\end{array}$} \\
\hline \multirow[t]{2}{*}{ ICD-10 } & \multirow[t]{2}{*}{ Site description } & \multirow[t]{2}{*}{ Sex } & \multicolumn{2}{|c|}{ United Kingdom } & \multicolumn{2}{|c|}{ England } & \multicolumn{2}{|c|}{ Wales } & \multicolumn{2}{|c|}{ Scotland } & \multicolumn{2}{|c|}{$\mathrm{N}$ Ireland } \\
\hline & & & Number & Rate & Number & Rate & Number & Rate & Number & Rate & Number & Rate \\
\hline \multirow[t]{2}{*}{ C00-C97 } & All malignancies & $M$ & 80,047 & 217.6 & 65,987 & 213.5 & 4,426 & 224.3 & 7,685 & 253.8 & 1,949 & 219.7 \\
\hline & & $F$ & 73,620 & 155.0 & 60,333 & 152.2 & 4,052 & 160.4 & 7,403 & 179.1 & 1,831 & 154.2 \\
\hline \multirow[t]{2}{*}{$\mathrm{C} 00-\mathrm{C} 14$} & Lip, mouth and pharynx & $M$ & 1,323 & 3.9 & 1,042 & 3.7 & 75 & 4.3 & 171 & 6.0 & 35 & 4.1 \\
\hline & & $\mathrm{F}$ & 690 & 1.5 & 559 & 1.5 & 35 & 1.5 & 76 & 1.9 & 21 & 1.8 \\
\hline \multirow[t]{2}{*}{ C15 } & Oesophagus & M & 4,794 & 13.3 & 3,935 & 13.0 & 257 & 13.4 & 499 & 16.6 & 103 & 11.8 \\
\hline & & $\mathrm{F}$ & 2,566 & 4.9 & 2,080 & 4.8 & 146 & 5.2 & 289 & 6.5 & 51 & 3.8 \\
\hline \multirow[t]{2}{*}{ C16 } & Stomach & $M$ & 3,464 & 9.2 & 2,804 & 8.9 & 217 & 10.9 & 345 & 11.2 & 98 & 11.0 \\
\hline & & $\mathrm{F}$ & 2,149 & 4.0 & 1,705 & 3.8 & 136 & 4.5 & 240 & 5.4 & 68 & 5.2 \\
\hline \multirow[t]{2}{*}{ C18-C20 } & Colorectal & $M$ & 7,488 & 20.2 & 6,030 & 19.4 & 387 & 19.5 & 845 & 27.8 & 226 & 25.6 \\
\hline & & $\mathrm{F}$ & 6,640 & 12.7 & 5,412 & 12.3 & 327 & 11.6 & 705 & 15.7 & 196 & 15.4 \\
\hline \multirow[t]{2}{*}{$\mathrm{C} 25$} & Pancreas & $M$ & 3,502 & 9.7 & 2,944 & 9.7 & 190 & 9.8 & 284 & 9.4 & 84 & 9.7 \\
\hline & & $\mathrm{F}$ & 3,726 & 7.6 & 3,129 & 7.6 & 197 & 7.3 & 311 & 7.5 & 89 & 7.1 \\
\hline \multirow[t]{2}{*}{ C32 } & Larynx & $M$ & 628 & 1.8 & 492 & 1.7 & 41 & 2.2 & 76 & 2.6 & 19 & 2.1 \\
\hline & & $\mathrm{F}$ & 166 & 0.4 & 129 & 0.3 & 8 & 0.3 & 25 & 0.6 & 5 & 3 \\
\hline \multirow[t]{2}{*}{ C34 } & Lung & $M$ & 19,559 & 53.3 & 15,793 & 51.2 & 1,087 & 55.1 & 2,169 & 71.2 & 511 & 57.4 \\
\hline & & $\mathrm{F}$ & 14,064 & 30.5 & 11,148 & 28.9 & 762 & 31.7 & 1,828 & 45.1 & 325 & 28.6 \\
\hline \multirow[t]{2}{*}{$\mathrm{C} 43$} & Melanoma of skin & M & 1,013 & 3.0 & 842 & 2.9 & 56 & 3.2 & 90 & 3.1 & 26 & 3.0 \\
\hline & & $\mathrm{F}$ & 804 & 1.9 & 674 & 1.9 & 47 & 2.2 & 66 & 1.7 & 16 & 1.4 \\
\hline C50 & Breast & $\mathrm{F}$ & 12,429 & 28.3 & 10,345 & 28.2 & 665 & 28.4 & 1,111 & 29.0 & 308 & 28.1 \\
\hline C53 & Cervix & $\mathrm{F}$ & 1,035 & 2.6 & 836 & 2.5 & 63 & 3.3 & 107 & 3.1 & 29 & 2.7 \\
\hline C54 & Uterus & $\mathrm{F}$ & 1,158 & 2.4 & 957 & 2.4 & 76 & 3.1 & 107 & 2.5 & 18 & 1.5 \\
\hline C56 & Ovary & $\mathrm{F}$ & 4,356 & 10.2 & 3,601 & 10.1 & 231 & 10.0 & 398 & 10.3 & 126 & 11.8 \\
\hline C61 & Prostate & $M$ & 10,094 & 25.7 & 8,521 & 25.7 & 565 & 26.3 & 782 & 25.1 & 225 & 24.8 \\
\hline C62 & Testis & $M$ & 78 & 0.3 & 60 & 0.2 & 6 & 3 & 10 & 0.4 & 2 & 3 \\
\hline \multirow[t]{2}{*}{ C64 } & Kidney & M & 2,126 & 6.0 & 1,752 & 5.9 & 125 & 6.7 & 194 & 6.5 & 54 & 6.3 \\
\hline & & $\mathrm{F}$ & 1,307 & 2.8 & 1,052 & 2.7 & 70 & 2.7 & 150 & 3.6 & 35 & 3.1 \\
\hline C67 & Bladder & M & 3,154 & 8.2 & 2,655 & 8.2 & 165 & 7.9 & 279 & 9.0 & 55 & 6.1 \\
\hline & & $\mathrm{F}$ & 1,642 & 2.9 & 1,360 & 2.8 & 88 & 2.7 & 163 & 3.3 & 32 & 2.2 \\
\hline C71 & Brain & M & 2,047 & 6.2 & 1,692 & 6.1 & 100 & 5.8 & 205 & 7.3 & 49 & 5.8 \\
\hline & & $\mathrm{F}$ & 1,399 & 3.7 & 1,154 & 3.7 & 75 & 3.9 & 138 & 4.1 & 32 & 3.3 \\
\hline C81-C96 & Lymphomas and leukaemias & M & 6,339 & 17.5 & 5,345 & 17.5 & 327 & 16.7 & 517 & 17.4 & 150 & 16.8 \\
\hline & & $\mathrm{F}$ & 5,379 & 10.9 & 4,474 & 10.9 & 282 & 10.9 & 486 & 11.3 & 136 & 10.8 \\
\hline C81-C85 & Lymphomas & M & 2,516 & 7.0 & 2,134 & 7.1 & 115 & 6.0 & 207 & 7.0 & 59 & 6.6 \\
\hline & & $\mathrm{F}$ & 2,243 & 4.6 & 1,862 & 4.6 & 111 & 4.3 & 210 & 4.9 & 61 & 4.8 \\
\hline C81 & Hodgkin's disease & M & 177 & 0.5 & 149 & 0.5 & 6 & 3 & 17 & 0.6 & 5 & 3 \\
\hline & & $\mathrm{F}$ & 133 & 0.3 & 111 & 0.3 & 7 & 0.4 & 11 & 0.3 & 4 & 3 \\
\hline C82-C85 & Non-Hodgkin's lymphoma & $M$ & 2,339 & 6.5 & 1,985 & 6.6 & 109 & 5.7 & 191 & 6.4 & 54 & 6.1 \\
\hline & & $\mathrm{F}$ & 2,110 & 4.3 & 1,751 & 4.3 & 103 & 3.9 & 199 & 4.6 & 57 & 4.4 \\
\hline C90 & Multiple myeloma & $M$ & 1,334 & 3.6 & 1,111 & 3.6 & 70 & 3.4 & 112 & 3.7 & 42 & 4.7 \\
\hline & & $\mathrm{F}$ & 1,212 & 2.4 & 1,005 & 2.4 & 68 & 2.6 & 108 & 2.3 & 30 & 2.4 \\
\hline C91-C95 & Leukaemia & M & 2,412 & 6.6 & 2,035 & 6.7 & 139 & 7.1 & 191 & 6.4 & 48 & 5.4 \\
\hline & & $\mathrm{F}$ & 1,882 & 3.8 & 1,572 & 3.8 & 101 & 3.9 & 164 & 4.0 & 45 & 3.5 \\
\hline
\end{tabular}

1 Using the European standard population.

2 All numbers and rates in this table are calculated as three-year averages.

3 Directly age-standardised rates were considered unreliable and were not calculated when there were fewer than 20 deaths over three years in an area. 

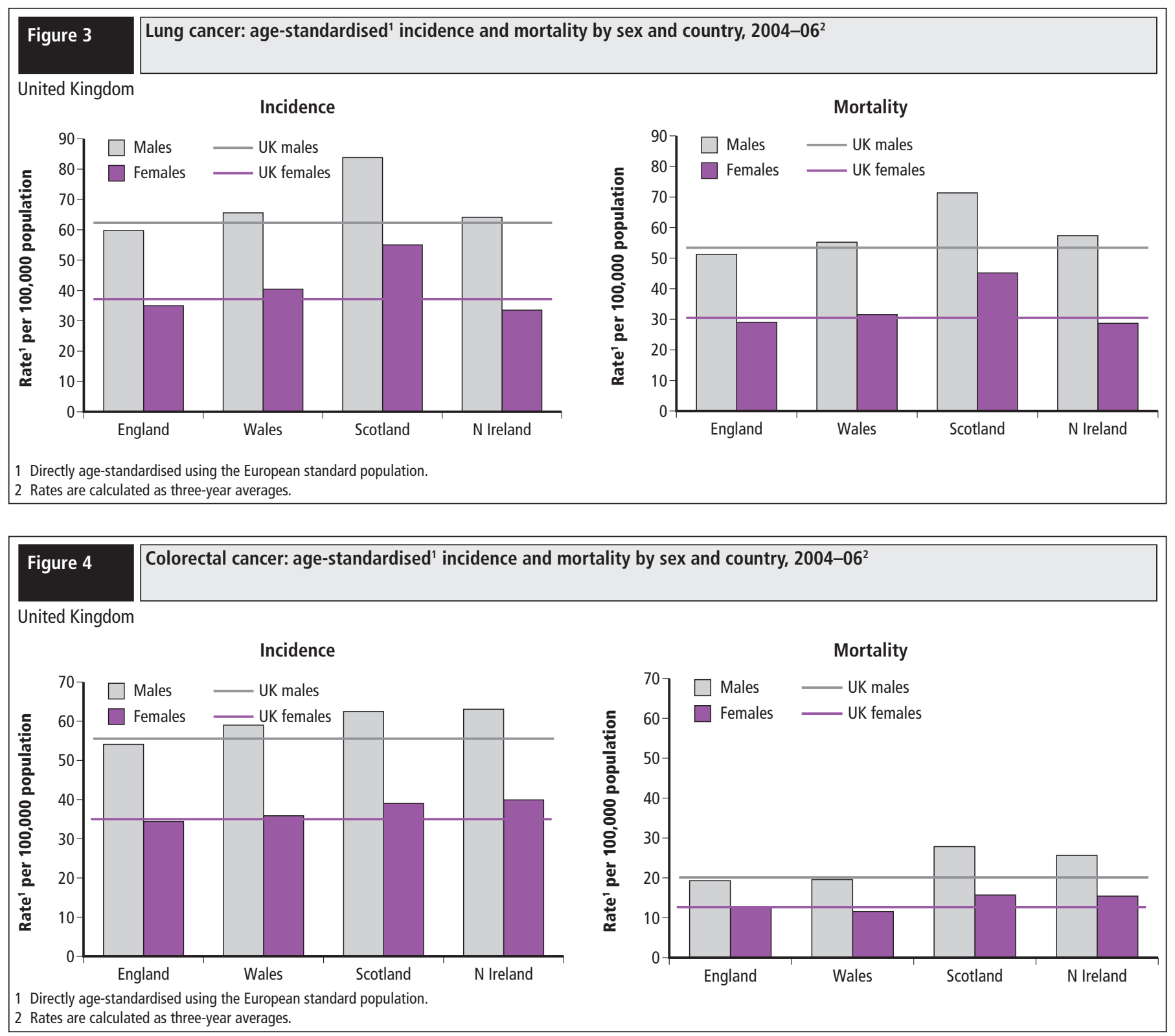

cancer mortality rates for males were similar in Scotland, Wales and Northern Ireland, but lower in England. Female mortality rates were similar in Scotland and Northern Ireland, but a little lower in Wales and England.

Overall cancer incidence and mortality rates for England were similar to those for the UK, since the cases and deaths for England accounted for more than 80 per cent of the UK total.

Wales had the highest overall cancer incidence rate for males in the UK. The incidence of prostate cancer was 15 per cent higher for Wales than for the UK as a whole, though mortality from prostate cancer was only 2 per cent higher. The apparently large difference between Wales and the UK in the incidence of bladder cancer does not necessarily reflect a true difference: certain types of bladder cancer are registered as malignant in Wales, ${ }^{1}$ but classified as benign elsewhere. In both males and females, mortality from bladder cancer was slightly lower than for the UK as a whole. Mortality rates for cancers of the larynx, cervix and uterus were much higher in Wales than in the UK.
In Scotland, the overall cancer mortality rates for both sexes were around 16 per cent higher than those for the UK as a whole, and the overall cancer incidence rates were 8 per cent higher.

- The incidence of lung cancer was 34 per cent higher for males and 49 per cent higher for females than in the UK as a whole. The incidence of, and mortality from, other smoking-related cancers oesophagus, lip, mouth and pharynx, and larynx - were also higher in Scotland than in the other countries of the UK. The incidence of prostate cancer was 14 per cent lower in Scotland than in the UK as a whole.

- The mortality rate for lung cancer in Scotland was 34 per cent higher for males and 48 per cent higher for females than in the UK as a whole. In males it was nearly three times the mortality rate for prostate cancer and in females it was 56 per cent higher than the mortality rate for breast cancer. Male mortality from colorectal cancer was 38 per cent higher in Scotland than in the UK and female mortality from cancer of the kidney and stomach was 29 and 35 per cent higher, respectively. 

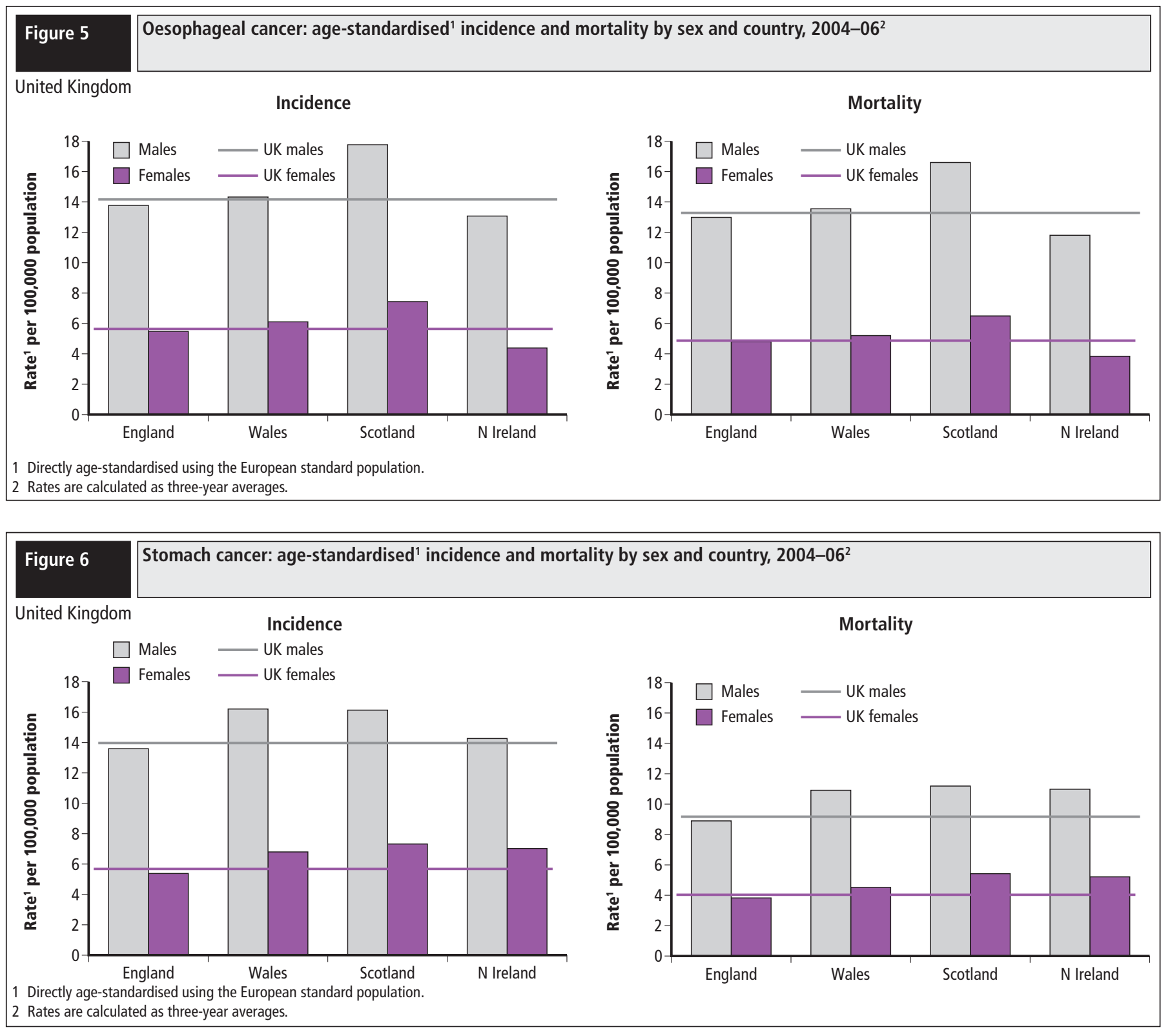

In Northern Ireland, overall incidence and mortality rates were very close to those for the UK as a whole. The rates for colorectal cancer were higher than those for the UK; incidence was 14 per cent higher in both males and females while mortality was 27 per cent higher in males and 21 per cent higher in females. The mortality rate for bladder cancer was 26 per cent lower in males compared with the UK as a whole, and 24 per cent lower in females. The incidence and mortality rates for breast cancer were the lowest in the UK.

\section{Previously published data}

UK data for 2003-05 were published in Health Statistics Quarterly $40 .^{2}$ Additionally, ONS has analysed trends in UK incidence and mortality $1993-2004 .^{3}$

\section{Acknowledgements}

These analyses have been produced with the assistance of the Welsh Cancer Intelligence and Surveillance Unit, the Scottish Cancer Registry and the Northern Ireland Cancer Registry. The National Cancer Intelligence Centre (NCIC) at the Office for National Statistics gratefully acknowledges their assistance. The NCIC also acknowledges the work of the regional cancer registries in England, and their close cooperation with the national registry.

\section{Cancer Registries in the United Kingdom}

Welsh Cancer Intelligence and Surveillance Unit

Scottish Cancer Registry

Northern Ireland Cancer Registry

\section{Regional Registries in England}

Northern and Yorkshire Cancer Registry

Trent Cancer Registry

Eastern Cancer Registration and Information Centre

Thames Cancer Registry

Oxford Cancer Intelligence Unit

South West Cancer Intelligence Service

West Midlands Cancer Intelligence Unit

North West Cancer Intelligence Service 


\section{Background notes}

1. Incidence and mortality rates have been directly age-standardised, using the European standard population, to control for differences in the age structure of the population between countries, and over time, to allow unbiased comparisons between rates.

2. The Office for National Statistics has been advised, both by expert epidemiologists and by members of the Advisory Committee on Cancer Registration, that non-melanoma skin cancer (ICD-10 C44) is greatly under-registered. Registration varies widely depending on a registry's degree of access to out-patient records and general practitioners. Incidence figures given in this report for 'all cancers' therefore exclude non-melanoma skin cancer.

3. The incidence figures in this report are those published at the time of the annual statistical releases. The cancer registration systems are live databases. Therefore, the figures presented here may not reflect those on the live databases.

4. Numbers and rates presented in this report have been calculated as three-year averages to reduce the effects of random variation in small numbers over time.

5. These data are available on the Office for National Statistics website at: www.statistics.gov.uk/statbase/Product.asp?vlnk=14209

\section{References}

1. Cooper N and Cartwright R (2005) 'Bladder' in Cancer Atlas of the United Kingdom and Ireland 1991-2000: Studies on Medical and Population Subjects no. 68, Palgrave Macmillan: Basingstoke. Available on the Office for National Statistics website at: www.statistics.gov.uk/statbase/Product.asp?vlnk=14059

2. Office for National Statistics (2008) 'Report: Cancer incidence and mortality in the United Kingdom and constituent countries, 2003-05', Health Statistics Quarterly 40, 91-97. Available on the Office for National Statistics website at: www.statistics.gov.uk/statbase/Product.asp?vlnk=6725

3. Westlake S and Cooper N (2008) 'Cancer incidence and mortality: trends in United Kingdom and constituent countries, 1993 to 2004', Health Statistics Quarterly 38, 33-43. Available on the Office for National Statistics website at:

www.statistics.gov.uk/statbase/Product.asp?vlnk=6725 